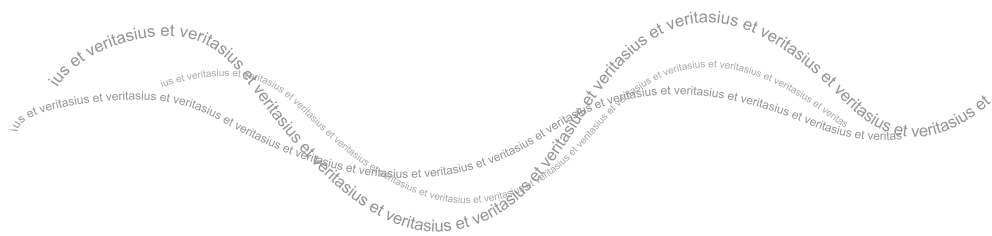

\title{
el Régimen Presidencial en la Constitución de $1993^{(*)}$
}

\section{The Presidential Regime in the 1993 Constitution}

Resumen: En el presente artículo, el autor realiza un análisis crítico del régimen político en la Constitución de 1993. Comienza analizando la institución de la presidencia de la República, junto con sus vicios y defectos, criticando así la concentración de poder en la figura del Presidente y el manejo autoritario de sus atribuciones, características que carecen de sentido en un Sistema Republicano. Así concluye con una nueva visión de la figura del Presidente de la República y sus atribuciones para lograr una mejora en el funcionamiento y eficiencia del Estado, sin afectar el equilibrio democrático.

Palabras Clave: Democracia - Régimen Presidencial - Constitución - Estado - Poder - Gobierno

\begin{abstract}
In this article, the author makes a critical analysis of the political regime in the 1993 Constitution. He begins analyzing the institution of the Presidency of the Republic, along with its vices and defects, criticizing the concentration of power in the figure of the President and the authoritarian management of his attributions, characteristics that are meaningless in a republic system. Thus, he concludes with a new vision of the figure of the President of the Republic and his attributions in order to achieve an improvement in the functioning and efficiency of the State, without affecting the democratic balance.
\end{abstract}

Keywords: Democracy - Presidential Regime - Constitution - State - Power - Government

${ }^{*}$ Abogado por la Pontificia Universidad Católica del Perú. Licenciado en Ciencia Política por la Universidad de Grenoble, Francia. Doctor en Derecho por la misma casa de estudios. Ex senador de la República. Ex presidente de la Comisión de Derechos Humanos de las Naciones Unidas. Ex miembro de la Comisión de la Verdad y Reconciliación. Profesor en la Facultad de Derecho de la Pontificia Universidad Católica del Perú. Experto en Derecho Constitucional y Ciencia Política. Director Ejecutivo de la Comisión Andina de Juristas. Correo electrónico: ebernal@pucp.edu.pe

${ }^{(* \star *}$ Nota del Editor: El artículo fue recibido el 30 de octubre de 2016 y aprobada su publicación el 26 de noviembre del mismo año. 


\section{Introducción}

El presente estudio pone al día el análisis sobre las características del régimen político en la Constitución de 1993. El título del trabajo se refiere al régimen presidencial, porque es el modelo que prevalece en la Constitución vigente. Pero el análisis constata la existencia de heterodoxias en el modelo del régimen presidencial, en razón de las orientaciones predominantes exacerbado por tradiciones seculares en la política en el Perú, la adhesión popular al caudillismo y un cierto paternalismo autoritario que lleva al Presidente de la República a darle un manejo autoritario a sus atribuciones constitucionales, donde la tendencia a la concentración del poder en su persona es visible.

En el análisis, se critica que el Presidente de la República sea a la vez jefe de Estado, personalice a la Nación, extremo que se dice carece de sentido en un sistema republicano, y sea también jefe de gobierno, factor que en la práctica neutraliza al Consejo de Ministros y a quien sea su presidente y de paso a los ministros que, se señala, para todo efecto práctico devienen en meros colaboradores o secretarios del Presidente de la República.

En la conclusión del análisis, se aboga por una redefinición constitucional del régimen político peruano, en cuyo contexto el Presidente de la República tenga una relación más estable y de colaboración con el Poder Legislativo, pero también con los demás órganos y organismos del Estado. Todo ello, se advierte, tendrá que darse a través de cambios progresivos en un proceso que otorgue mayor sentido de responsabilidad social, de institucionalidad a la presencia y participación política de la sociedad peruana.

La bibliografía sobre la naturaleza y características de la institución del Presidente de la República en el Perú es rica, abundante y valiosa. Historiadores como Jorge Basadre; humanistas integrales como Víctor Andrés Belaunde; constitucionalistas de gran erudición ubicados en varias generaciones de notables: Alzamora, Paz Soldán, Villarán, Ferrero, Herrera Paulsen o en las últimas décadas Rubio Correa, García Toma, Borea, Landa, Eguiguren; sociólogos y politólogos de renombre: Cotler, Ames, Neira, Planas, Tanaca, Pease, y otros, que hacen más larga la lista de notables que han aportado análisis relevantes sobre este cargo, sin duda el más importante del Sistema Político Republicano. Cabe cuestionarse, ¿para qué gastar más tinta en una institución tan estudiada?

\section{Los problemas del Estado}

La respuesta es que no dudo, sino más bien asumo y hago mías todas estas opiniones ilustradas, que en conjunto multidisciplinario nos han proporcionado un conocimiento certero y a veces una dura y necesaria crítica, al modo como se ha implementado esta institución del Presidente en el Perú y a quienes ocuparon el cargo sin merecerlo o lo orientaron hacia prácticas y estilos de ejercer el poder, como si ser Presidente del Perú no fuese otra cosa que el ejercicio omnímodo de potestades que, como bien dice Víctor Andrés Belaunde, convirtieron al Presidente en un Virrey sin Rey y corona, y que con solo banda y cetro, desnaturalizaban el cargo hasta llevarlo a excesos autoritarios, ajenos a lo dispuesto en las constituciones vigentes en el respectivo turno presidencial (Belaunde 1994).

Estos excesos, muchas veces aplaudidos por sectores sociales que encarnaban en una autoridad todo poderosa la posibilidad de ser atendidos en numerosas necesidades insatisfechas, afectaron sustancialmente el equilibrio democrático entre los poderes constitucionales del Estado. Y si originariamente se tomó de los Estados Unidos el modelo del régimen republicano presidencial, en la práctica histórica del país el régimen político devino en un presidencialismo prácticamente absoluto, con áulicos palaciegos, funcionarios dóciles a la voluntad del gobernante de turno, mucho espectáculo cortesano y bastante circo, aunque con poco pan, salvo uno que otro populismo asistencialista.

La deformación ocurrida con la Presidencia de la República convirtió la democracia y la promesa de la vida republicana de la que nos habla Basadre, en unos paréntesis de 


\section{Enrique Bernales Ballesteros}

escasa duración. Entre presidentes caprichosos y autoritarios y golpes de estado, fruto de las intrigas oligárquicas y de las vanidades de caudillos militares, se perdió mucho tiempo, tal vez demasiado, aunque como nos recuerda Marcel Proust, nunca es vano el esfuerzo de luchar por la recuperación del tiempo perdido (Proust 1970).

Es en este esfuerzo de ser por fin una democracia plena, que reparo en lo interesante que es el haber logrado que estos 16 primeros años del siglo XXI, el Perú haya experimentado una transición a la democracia, inaugurada por Valentín Paniagua desde la presidencia constitucional que ocupara por designación del Congreso, luego del fin del fujimorato. Esta generosa preocupación de Paniagua ha significado una inusual continuidad de gobiernos elegidos $(2001,2006,2011$ y 2016) que nos hace pensar que algo finalmente ha comenzado a cambiar en los hábitos políticos del país.

Pero en medio de la legítima expectativa que despierta esta continuidad que es anuncio de avance en la construcción de democracia y de estabilidad política, nos genera preocupación dos situaciones que califico de problemáticas. La primera es que en estos dieciséis años de democracia no hayamos sido capaces de llevar a cabo una cabal reforma del Estado; la segunda, tributaria de la primera en parte, es esa miopía que impide ver los vicios y defectos que acompañan el ejercicio de la Presidencia de la República.

En lo referente al Estado, el que tenemos no funciona, no llega a tener presencia en todo el territorio y menos a atender a la totalidad de la población. Su ausencia se hace sentir en las deficiencias que son visibles en servicios básicos como la educación, la salud, el saneamiento, la estructura territorial tan atrasada y que es una grave rémora para la integración del país; y para colmo de los males que justifican la irritación ciudadana en el deficiente funcionamiento del Estado se suman tres graves problemas más: la inseguridad, la corrupción que se manifiesta en todos los niveles y como corolario una creciente crisis de institucionalidad, que amenaza si no hacemos nada por conjurarla con llevarnos a una situación de anomia.

Se dirá: "pero hemos tenido crecimiento económico", lo cual es cierto, aunque no se debe ocultar que el beneficio ha sido inmensamente desigual y ha favorecido especialmente a los que más tienen; ique el turismo hacia el Perú ha subido exponencialmente pasando de menos de un millón de visitantes a comienzos de este siglo, a poco más de tres millones en la actualidad! Pero el Presidente Kuczynski tiene razón cuando reclama que lleguemos a por lo menos siete millones. $Y$ es que, a pesar de nuestras falencias, Cuzco y Macchu Picchu están en el Perú, lo mismo que Chan Chan, Kuelag, el Colca, la Amazonía, y todo ese inmenso patrimonio cultural que nos pone junto con México a la cabeza de la riqueza patrimonial latinoamericana. Y pensar que Costa Rica, país pequeño y con apenas tres millones de habitantes recibe un promedio anual de veinte millones de visitantes. Pero el rosario de las desdichas podría convertirse en interminable y vergonzoso si se nos ocurriera contrastar la excelente gastronomía nacional con el cuadro de desnutrición infantil que afecta al país, la penosa situación del deporte con la incompetencia para organizar adecuadamente los Juegos Panamericanos del 2019; la incapacidad para sacar de la informalidad al $70 \%$ de la población laboral o el espantoso colapso del tránsito, no solo en Lima, sino en casi toda la costa y también en Cuzco, Arequipa, Huancayo, Iquitos, Pucallpa, etcétera.

No es para congratularnos la constatación del estado de un país que gasta en fanfarrias desarrollistas, cuando aún son muchas las tareas que tenemos por delante para que el Perú se convierta en un país sólidamente desarrollado. Pero mencionar algunos de los problemas sustantivos que nos sustentan, no debiera ser utilizado para el desaliento, que de nada sirve y menos para convertirnos en antisistema que en ninguna parte ha logrado cambiar lo que estaba mal, salvo para transformarlo en desastre nacional. En síntesis, los dieciséis años de democracia precaria muestran que a pesar de las flaquezas y debilidades subsistentes hemos descubierto que somos capaces de perseverar en la decisión de tener un Estado Democrático, con estabilidad gubernamental y fortaleza para 
seguir defendiendo la legalidad constitucional, a pesar de gobiernos como los de Toledo y Humala que han terminado sus mandatos afectados por denuncias que la justicia está investigando.

Se trata entonces de abrigar esperanzas no basadas en ilusiones, sino en aquellas posibilidades concretas y certeras que se ofrecen hoy al Perú actual. De allí los deseos de éxito al gobierno instalado el ultimo 28 de julio, en la expectativa vigilante y crítica, de que cumpla con el programa de gobierno ofrecido al país, en un contexto de transparencia, justicia y eficacia.

Bajo esta perspectiva, nos permitimos desde estas líneas escritas hacer un análisis sobre la situación jurídica y política del país, con el propósito de contribuir a la mejora de la eficacia y la transparencia en la gestión pública. No desconocemos la importancia del discurso político, pero este tendrá siempre que pasar por la prueba de la voluntad política y la veracidad, ambos elementos que al menos en el corto plazo nacional debieran concretarse en dos reformas sustantivas que comprenden varios asuntos cruciales del patrón estructural del Estado peruano, que urge modificar: en primer lugar, la desburocratización de la administración pública y sus procedimientos, para lo cual será indispensable revisar y poner al día la ley del poder Ejecutivo; hacer un trabajo de revisión integral de la legislación vigente (leyes, decretos legislativos, decretos supremos, resoluciones supremas y directorales, etcétera) de modo que se deje vigente solo lo estrictamente necesario; revisar la ley de Servir, limpiarla de las excepciones que contempla y trabajar en serio por la importancia de la carrera pública y la meritocracia; en segundo lugar, revisar íntegramente el proceso de descentralización de modo que se encuentre el camino hacia las macro regiones, la conexión entre el gobierno nacional y los sub nacionales; la capacitación de los recursos humanos, preparándolos en la planificación y ejecución de programas de desarrollo regional, en fin buscar los consensos necesarios para una revisión racional de la Constitución vigente, pues pese a las reformas parciales y a los aportes de la jurisprudencia constitucional, ella aún contiene excesos que retardan la modernización del Estado y la democratización de la sociedad.

\section{El Presidencialismo a la peruana}

Llegado al punto anterior, es momento de ocuparnos del sistema presidencial, tal cual se registra de constitución en constitución, sin que el modelo vigente tenga la excelencia que aconseja mantener la carta, tal como ella está.

Nos concentraremos en el análisis de la institución de la Presidencia de la República, a partir de lo que sobre ella dispone la Constitución vigente. Lo primero es tener en cuenta que en su versión originaria, esta Carta, nacida de un golpe de Estado, dado por quien detentaba el cargo de Presidente Constitucional de la República (05/04/1992), fue concebida para prolongar hasta donde fuera posible la presidencia del ingeniero Alberto Fujimori en el Poder Presidencial. Para cumplir ese propósito, había que modificar el artículo 112 de la Constitución que en su versión original no autorizaba la reelección inmediata del Presidente de la República.

En realidad, la elección de 1995 debió significar que finalizaba el gobierno de Fujimori, elegido presidente en 1990 con un mandato constitucional que no autorizaba la reelección inmediata. La nueva Constitución elaborada por el Congreso Constituyente Democrático (CCD), órgano que debió crear Fujimori para cumplir con el compromiso adquirido en la reunión especial de la conferencia de Ministros de Relaciones Exteriores de los países miembros de la OEA, realizado el 18 de marzo de 1992 en las Bahamas, regía desde el momento de su promulgación. Carecía, como toda ley, de efectos retroactivos, pero la mayoría fujimorista que controlaba el Congreso no solo modificó el artículo 112 de la Constitución y autorizó la reelección inmediata, sino que autorizó una interpretación que permitía la reelección inmediata de Fujimori, considerándola como la primera de manera que para el año 2000 Fujimori podía volverse a presentar como si fuese su primera reelección inmediata. Que el Tribunal Constitucional se opusiera a esa interpretación, solo sirvió para que el régimen autoritario y el Parlamento destituyesen a 


\section{Enrique Bernales Ballesteros}

los tres magistrados constitucionales que se oponían a ese despropósito (Aguirre Roca, Rey Polis y Revoredo Marzano).

Recién con la caída de Fujimori y en el periodo de transición a la democracia, inaugurado bajo la presidencia de Valentín Paniagua, se modificó el artículo 112 para reponer el texto adoptado desde la Constitución 1933, que fue respetado por la carta de 1979, esto es, la prohibición de la reelección inmediata y que solo transcurrido otro periodo constitucional como mínimo, el ex presidente podía volver a postular. Pero un análisis sistemático del texto constitucional vigente nos muestra que la tendencia a concentrar capacidades y atributos de poder en el Presidente de la República, que por lo demás están presentes a lo largo de la historia constitucional del Perú, se reiteran en la carta vigente, al punto de distorsionar el régimen presidencial originalmente concebido como equilibrio de poderes y la distribución funcional de responsabilidades entre los órganos políticos del Estado. Pero este no fue el caso peruano donde desde el siglo XIX las constituciones adoptaron un modelo de concentración de facultades en el Presidente de la República, al extremo de configurar un régimen político presidencialista que otorga excesivos atributos individualizados en la institución de la presidencia, excede los límites que la teoría liberal conceptuó para un régimen político republicano, laico, de equilibrio funcional en la conducción de los asuntos públicos y ajeno a las tentaciones de una concentración de poder incompatible con la división funcional de los poderes del Estado y el equilibrio en los atributos de poder y su ejercicio por cada órgano de gobierno del Estado.

La prueba de esta tesis la encontramos en varios de los dispositivos constitucionales que se refieren al Poder Ejecutivo, que ponen de manifiesto una concentración de capacidades, de decisión, garantías de inmunidades y pompas protocolares que concentran de un modo estrictamente personalizado el poder que detenta el Presidente, tendiendo en torno a su persona una especie de encarnación de la soberanía, de plenitud jerárquica y de promoción del culto popular rodeando al Presidente. De esta manera, la institución termina pareciéndose a los patrones del trato monárquico que además de impropio, lo aleja de la horizontalidad que caracteriza a las democracias contemporáneas.

Analicemos algunos de estos dispositivos.

Artículo 110.- "El presidente de la República es el jefe del
Estado y personifica a Nación" (primer párrafo).

La primera parte del enunciado proviene de la Constitución de 1933 que se repite en las Constituciones de 1979 y 1993 que convierte al Presidente de la República en Jefe de Estado. En la tradición de las constituciones peruanas del siglo XIX, la fórmula empleada era la de considerarlo como "jefe del Ejecutivo". La tesis subyacente en esta denominación era de inspiración ortodoxamente liberal al concentrar las atribuciones del cargo en las atribuciones ejecutivas, elemento que incidía en la separación de poderes y no otorgándole primacía al presidente en relación con los presidentes de los otros poderes del Estado, razón por la que, como se deduce, no se le atribuía al Presidente la calidad de jefe de Estado. Esta opción, desde un punto de vista de la teoría constitucional es correcta, pero no reparó en que en un país acostumbrado al poder de los Incas y luego de los virreyes, la vocación popular proveniente de tradiciones tan jerárquicas, siempre ha tendido a considerar al Presidente de la República como un cargo absolutamente superior al de todos los demás; es decir, un jefe de Estado y no solo del Ejecutivo, en este sentido nos parece preferible que las constituciones del siglo $\mathrm{XX}$ hayan entregado al Presidente de la República los atributos de jefe de Estado.

En efecto, proviene de la historia de nuestro país, el cambio de Jefe del Ejecutivo a Jefe del Estado, forjándose así un cause constitucional más amplio, sólido y también necesario en la perspectiva de fortalecer la autoridad del Estado (Bernales 2012, 543). En este aspecto, coincido con el planteamiento de Jorge Basadre y Víctor Andrés Belaunde, que coinciden al señalar el enraizamiento profundo del Presidente de la República como una autoridad que en muchos aspectos venía a ser el heredero en el colectivo popular del 
El Régimen Presidencial en la constitución de 1993 The Presidential Regime in the 1993 Constitution

Virrey y del Inca. El caudillismo presidencial y la tendencia a concentrar poderes en esta institución, más allá de los reparos y cuidados constitucionales tienen que ver más con la sociología y la historia que con la Constitución.

En este sentido es que nos parce más realista lo dispuesto en las cartas de 1993, 1979 y 1993 que señalan, más allá de algunos excesos en esta última, que el Presidente de la República no solo es Jefe del Ejecutivo, sino una institución que políticamente es el eje del sistema constitucional. En el Perú, el régimen político tiende al predominio del Ejecutivo y es un dato corroborado por nuestra historia que, tratándose de criterios de poder y gobierno, el Presidente de la República suele imponer los suyos. $Y$ es que hay también en el presidencialismo peruano una vertiente caudillista, que es uno de los elementos claves de nuestra cultura política. Eso hizo decir a Climtom Rositer, que en el Perú, "el Presidente de la Republica es también padre de multitudes, oráculo de Delfos y héroe de la televisión" (Bernales 1999, 160).

En verdad, es difícil que una Constitución pretenda legitimarse forzando marchas a contracorriente de lo que son las tradiciones seculares de un pueblo y en esencia no nos parece ajeno a la actualización de ciertos esquemas liberales en los que cualquiera sea el régimen político que se adopte: presidencial norteamericano, mixto tipo francés o parlamentarios como los que predomina en Europa, el Presidente de la República tenga las características de Jefe de Estado, entendiendo por tal a una autoridad que encarne el orden, la legalidad, el respeto a la institucionalidad democrática y la continuidad republicana para arbitrar y resolver situaciones que puedan poner en peligro esos valores.

Pero si estamos de acuerdo con la caracterización del Presidente de la República como Jefe de Estado con facultades específicas y exclusivas del cargo, reiteramos nuestra crítica a la otra calificación que le otorga el artículo 110 al Presidente, al señalar "que personifica a la Nación". En la versión original de la comisión principal de la Asamblea Constituyente de 1979, la expresión que contenía el artículo 145 del ante proyecto era que "el Presidente de la República es el Jefe del Estado y el personero de la Nación". Esta definición era la adecuada. Por su alto cargo que proviene de la elección popular, es correcto que, junto a ser el Jefe del Estado, el Presidente de la República sea el personero de la Nación, en cuanto a reconocimiento de la importancia jerárquica del cargo y detentar la representación máxima del pueblo debiendo así ser reconocido.

Pero el cambio de personero a la tesis de que personifica a la Nación es un exceso no solo gramatical, sino sustantivo. En el libro "Constitución y Sociedad Política", aparece una fundamentada tesis que cuestiona la posibilidad jurídica y metafísica que el Presidente de la República personifique a la nación al punto que en esa perspectiva se constituya el mismo en la Nación (Rubio y Bernales 1983). Este planteamiento lo hemos reiterado en numerosos trabajos de análisis constitucional, pero consideramos pertinente retornar al comentario que aparece en mi libro "La Constitución de 1993: 20 años después". En efecto "personificar" es darle vida a una cosa general o abstracta, mediante la cual esta adquiere identidad o le es transferida una identidad. Si aplicamos el concepto al Presidente de la República, resultaría que la Nación, que en esencia somos todos, pero que al mismo tiempo por ser todos es un dato histórico, geográfico, etcétera, se corporativiza y adquiere cuerpo e identidad en el Presidente de la República, que siendo uno se convierte en todo, el pasa a ser la Nación sin dejar de ser al mismo tiempo un ciudadano particular (Bernales 2012).

Esta personificación del poder es una concepción explicable en teorías absolutistas. Bajo el absolutismo monárquico, aquel que se inspiraba en el origen divino de los reyes, el monarca era la Nación y el Estado, la síntesis está concedida en la famosa frase de Luis XIV "I'etat c'est moi" pero en una república el Presidente no es el Estado ni es la Nación. Puede ser el personero de una Nación, expresar el punto de vista a través del cual la Nación quiere ser una determinada cosa o presentar una demanda. Pero lo que es inaceptable es que se pretenda utilizar una figura por la cual el Presidente - Nación es el parapeto que protege al Presidente - persona. 


\section{Enrique Bernales Ballesteros}

En todo caso, la concentración del poder en el Presidente en nuestro sistema constitucional hace de él un ciudadano con amplísimas facultades. Además de personificar a la Nación, dirige la política general del gobierno, es el jefe de Estado, jefe de Gobierno y comandante supremo de las Fuerzas Armadas. Esta concentración excesiva de poder ha sido la fuente de autoritarismos despóticos y cesarismos presidenciales que priman hasta nuestros días.

Lamentablemente, nuestra Constitución está plagada de dispositivos que contienen excesos de prerrogativas presidenciales, que pueden llevar a situaciones de una no solo excesiva, sino también abusiva concentración del poder en quien ejerce este cargo. Situaciones de este tipo han existido y por lo general han sido peligrosas no solo para la estabilidad política de los gobiernos, sino también por perjuicios causados a ciudadanos que han sido víctimas de decisiones arbitrarias provenientes de una omnipotencia presidencial. La tendencia de quien actúa como presidente - nación, no tiene nada que ver con los sistemas democráticos, caracterizados más bien por la demanda de responsabilidades que la ciudadanía puede hacer a quienes ejercen una función pública. Como bien sabemos, las democracias republicanas son en esencia opuestas a los absolutismos monárquicos y a las costumbres cortesanas en las que en los viejos y superados tiempos se apoyaba la autoridad real y por todo esto no está de más recordar que los presidentes republicanos no son ni pueden ser reyes.

Pero veamos, aunque sea sucintamente, otros dispositivos constitucionales que a nuestro juicio ponen de manifiesto una concepción constitucional de concentración excesiva de poder en el Presidente de la República.

El artículo 115 en su segundo párrafo señala que: "Cuando el Presidente de la República sale del territorio nacional, el primer vicepresidente se "encarga del despacho".

La expresión "encargo del despacho" tiene diversas interpretaciones. Enrique Chirinos Soto por ejemplo sostenía que "encargo" significaba atender cuestiones de mero trámite, pero no asumir a plenitud las funciones del Presidente de la República (Chirinos 1994). No coincido con esta interpretación, porque gramaticalmente el término "encargo" si bien reconoce que la titularidad de una cosa corresponde a una persona, admite también que esa titularidad puede ser temporalmente delegada a una tercera persona que asume las funciones del principal.

En el caso de la ausencia temporal del Presidente, es obvio que el encargo comprende también las funciones, pues el Estado y el Gobierno del país no se paralizan por ausencia del Presidente de la República. Si por determinadas situaciones personales o por gestiones o representación en el exterior el Presidente viaja, es obvio que el Vicepresidente lo remplaza con las funciones inherentes al gobierno. No obstante, los partidarios del limitativo no son pocos; alegan algunos que al viajar el Presidente lo hace en ejercicio de sus funciones de representación del país, por lo que el encargo tiene que ser solo de despacho, en el sentido de tramitación de cosas, pero no de capacidad de toma decisiones. No falta inclusive quienes señalan que son varios los presidentes que al viajar al exterior dejan instrucciones expresas para que se habilite al vicepresidente una oficina, pero no la presidencial que es de uso exclusivo del titular. ¿Celo excesivo, temor, desconfianza? Difícil saberlo, pero lo concreto es que los vicepresidentes en el régimen político peruano carecen de funciones propias, tienen un cargo, pero no funciones.

El artículo 117 dispone que el Presidente de la República durante su periodo solo puede ser acusado por 4 causales: traición a la patria, impedir elecciones políticas, disolver el Congreso, salvo los casos previstos en el artículo 134 de la Constitución y por impedir su funcionamiento o los del Jurado Nacional de Elecciones y otros organismos del sistema electoral.

En realidad, este artículo es imperfecto; debe leerse conjuntamente con los artículos 99 y 100 de la Constitución que se refieren de un modo imperfecto al impeachment que no es otra cosa que el juicio político que conlleva sanciones a un alto cargo del Estado. En la tradición anglosajona, que es de donde proviene el impeachment, este no limita ni impide que el presidente, el vicepresidente 
y todos los funcionarios de Estados Unidos puedan ser acusados y condenados por traición, concusión y otros delitos. Así lo dispone la sección IV del artículo II de la Constitución Norteamericana. El artículo bajo comentario de la carta peruana omite la diferencia a los delitos comunes que pudiera cometer un alto cargo. Pero no por detentar esa condición puede estar exceptuado; la responsabilidad penal es siempre exigible a quien comete un delito, sea este en razón de la función o común.

El artículo 118 contiene numerosas atribuciones presidenciales y existen algunos dispositivos que significativamente no hacen otra cosa que reforzar los poderes presidenciales. Pasamos a comentarlos:

Inciso 3.- Este dispositivo proviene de la Constitución de 1979 y si fuimos críticos de ese texto, lo somos también de su reiteración en la Carta de 1993. En efecto, consideramos este dispositivo como una suma de más poder al que ya tiene el Presidente de la República como jefe de Estado, cargo desde el cual se ocupa de la alta política del Estado. ¿Dirigir la política general del gobierno significa ser también jefe de Gobierno y acaparar o inclusive ocuparse de todos los asuntos administrativos? Si así fuere esta concentración del Poder que reduce a los Ministros a funcionarios de segunda categoría, no reporta ningún beneficio a la eficiencia en la toma de decisiones políticas y administrativas. Si finalmente todos los asuntos de gobierno tienen que ser vistos y decididos por el Presidente de la República, ello repercutirá negativamente en la lentitud con la que se adoptan decisiones y en ineficiencia, que como se sabe es un viejo mal del Estado peruano.

Es un grave error concentrar la multiplicidad de los actos administrativos en una sola persona, como si la concentración fuese una virtud. Lo correcto es la distribución de responsabilidades y el que la administración pública sea efectivamente asumida por un colectivo, es decir, por un gabinete ministerial, al frente del cual, sea el Presidente del Consejo de Ministros quien se ocupe de coordinar los asuntos que competen a la gestión pública. De este modo, el Presidente de la República solo se ocuparía de las altas funciones correspondientes a la conducción del Estado.

Aun cuando la teoría constitucional registra varias modalidades de ser gobierno, históricamente la más eficiente es la que encarga al Gabinete la responsabilidad de compartir las funciones que competen a la gestión pública. La expresión gobiernos de gabinete se suele emplear para los regímenes parlamentarios, pero también puede ser asumido en los regímenes presidenciales cuando estos reservan al jefe de Estado funciones superiores a las del propio gobierno, contándose entre ellas la de arbitrar y resolver por encima de los órganos ejecutivo y legislativo.

El gobierno de los tiempos actuales se ha convertido en una tarea compleja y altamente especializada en todas las funciones y responsabilidades que asume, por lo tanto no puede reducirse su dirección a la responsabilidad exclusiva a una persona, de allí que como señalamos en el análisis de la Constitución de 1993, el gobierno debe radicar en el gabinete, que tendría la responsabilidad técnico - colectiva de gobernar, lo cual no medra la autoridad del jefe del Estado, ni lo excluye del gobierno; por el contrario, lo pre eleva, entre otras cosas para asegurar la continuidad, eficacia y direccionalidad del gobierno en la aplicación de los planes y programas ofrecidos por el Presidente de la República en el momento de su elección.

Inciso 5.- Convoca a elecciones para Presidente de la República, representantes al Congreso, alcaldes y Regidores.

Esta atribución es innecesaria concentrarla en el Presidente de la República; debe ser una función exclusiva de las instituciones que conforman el sistema electoral; tal el caso del Jurado Nacional de Elecciones (JNE) al que el artículo 176 de la Constitución lo reconoce como un órgano independiente y autónomo que se encarga del planeamiento, la organización y la ejecución de los procesos electorales. Estas competencias deben comenzar por las convocatorias a elecciones. Se trata de una autonomía funcional que no tiene por qué depender del Presidente de la República y que puede ser ocasión de retardos 


\section{Enrique Bernales Ballesteros}

perjudiciales, como sucedió en las recientes elecciones generales, donde el entonces presidente Humala retrasó hasta el último día posible la convocatoria a las elecciones generales.

Inciso 6.- Convocar al Congreso a legislatura extraordinaria y firmar, en ese caso, el decreto de convocatoria.

Este dispositivo es correcto pero incompleto. La Constitución de 1979 tenía un doble canal para la realización de legislaturas extraordinarias: por iniciativa presidencial o por decisión del Congreso cuando así los solicitaban por lo menos dos tercios del número legal de cada cámara.

La fórmula actual ha eliminado del ámbito constitucional la convocatoria por el Congreso y señala que es el Presidente de la República quien convoca al Congreso a legislatura extraordinaria. En la actualidad, el Congreso puede auto convocarse si cumple con los requisitos que le fija el Reglamento del Congreso. Pensamos que la capacidad del Congreso para auto convocarse debe ser una atribución constitucional y no reglamentaria, aunque el Reglamento del Congreso tenga fuerza de ley. Reflexionemos en los siguientes términos. Si la Constitución no contuviera la atención presidencial de convocar a legislatura extraordinaria, ¿sería suficiente que la autorización solo estuviese en la ley orgánica del Poder Ejecutivo? Recordemos al respecto que la organización y funcionamiento de poderes del Estado es materia constitucional. Las leyes de desarrollo constitucional tienen como punto de partida lo que ordena la Constitución, pero no cubren ni sustituyen los vacíos ni ausencias.

Inciso 14. Presidir el Sistema de Defensa Nacional; y organizar, distribuir y disponer el empleo de las Fuerzas Armadas y de la Policía Nacional.

Asumimos que esta atribución proviene de ser el Presidente, el Jefe supremo de las Fuerzas Armadas y la Policía Nacional. De esto se ocupan los artículos 164 y 167 de la Constitución y su tratamiento tendría mejor lugar en el capítulo XII que se ocupa de la seguridad y la defensa nacional. La observación apunta a tener en cuenta que la defensa nacional, tal como señala el artículo 164 constituye un sistema que contiene la dirección, preparación y el ejercicio de la defensa nacional, que a su vez está conformada por siete organizaciones que corresponden a distintos niveles de especialización militar. Teniendo en cuenta lo que esta composición y funciones significan en términos de burocracia y especialización de la gestión ¿Es factible que el Presidente de la República pueda dedicarle tiempo y ser eficiente para dirigir un aparato complejo que implica una autoridad constante y una gestión directa? Es obvio que el Presidente de la República debe tener una relación de superioridad jerárquica sobre las Fuerzas Armadas y la Policía Nacional, pero debiera encontrarse una fórmula que no sea mero formalismo y que en los hechos el Presidente delegue o conozca muy superficialmente los temas de la Defensa Nacional, por la imposibilidad de ocuparse directamente de este delicado sistema.

Inciso 19.- Se refiere a la facultad presidencial de dictar medidas extraordinarias mediante decretos de urgencia con fuerza de ley en materia económica y financiera.

La redacción de este inciso es deficiente, confusa en sus términos y peligroso su uso, pues puede prestarse a excesos si el Presidente de la República o su entorno gubernamental entendiese que mediante este inciso pudiera sustituir al Congreso en su actividad legislativa y para todo efecto práctico comportarse con una autonomía de decisión ajena a lo que la democracia aconseja(1) (Bernales 2012). Las funciones legislativas del Congreso de la Republica deben ser siempre respetadas. No se trata de negar que la realidad puede impedir la dación de medidas extraordinarias de urgencia social, pero ello debe ser siempre fruto de un uso inteligente y prudente y de una cuidadosa coordinación entre el Ejecutivo y el Legislativo.

(1) A este asunto nos referimos extensamente en Enrique Bernales, La Constitución de 1993: veinte años después (Lima: IDEMSA, 2012), 591-596. Nos remitimos a su lectura. 
Insistimos en que la fórmula empleada en este inciso no es adecuada. Pues el riesgo de que el control ex post del Parlamento no funcione adecuadamente es un peligro real. En efecto, este inciso señala simplemente que "el Congreso puede modificar o derogar los referidos decretos de urgencia, pero este criterio no se refiere a trámite de control alguno, sino simplemente a la función ordinaria del Congreso de dar leyes, modificarlas o derogarlas.

Por otra parte, no queda clara la circunstancia habilitante del estado de necesidad justificante de la expedición de un Decreto de Urgencia, que en realidad radica en que su finalidad es enfrentar una situación de emergencia, razón por la cual el dispositivo constitucional debiera insistir que los decretos de urgencia no son una facultad permanente pues su carácter y vigencia son transitorios.

Inciso 21: Conceder indultos y conmutar penas. Ejercer el derecho de gracia.

Este inciso se refiere exclusivamente al indulto, no a la amnistía, que en el derecho peruano está reservado al Congreso de la República. El indulto es la expresión o manifestación principal del derecho de gracia, que en realidad solo puede ser reconocido como un derecho del Estado que si bien es el titular del derecho a castigar por la comisión de un delito, tiene también en el ejercicio de su soberanía la capacidad, bajo determinadas condiciones, de perdonar la pena impuesta por los tribunales de justicia.

En esta materia, el derecho comparado nos informa de posiciones diferentes en cuanto a situaciones en las que el Estado puede hacer uso del indulto entendido como la capacidad de ejercer el derecho de gracia. En el derecho peruano, la gracia es una atribución constitucional que solo puede ser ejercida por el Presidente de la República, que no exige requisito legal alguno para concederlo. Es por consiguiente una facultad discrecional del Presidente de la República que la ejerce intuito personae; es decir, porque tiene la facultad per se de concederla. No obstante lo anterior, poco a poco se han introducido requisitos para que el presidente pueda decidir cómo, cuándo y a quién indulta: buena conducta del reo, solicitud de la gracia, cumplimiento parcial de la pena, edad avanzada o enfermedad terminal. Además, hay leyes que exceptúan de la gracia a condenados por secuestro agravado, terrorismo y narcotráfico.
Pero salvo estos tres tipos penales, los criterios limitativos de la autonomía presidencial, incluyendo los trabajos de las comisiones de estudios de expedientes que se forman en el Ministerio de Justicia, la práctica presidencial no entiende ni acepta como vinculantes las recomendaciones que en un sentido o en otro contengan los informes de las comisiones de indulto. No se discute que por razones de humanidad se concedan indultos, pero sí somos de la opinión que debe existir un régimen legal que precise las circunstancias, situaciones y procedimientos bajos los cuales se concede. No debe ser una potestad absoluta del presidente. Este no es Dios ni soberano para conceder y administrar una gracia que no viene de Dios, sino de los criterios que la ley dispone para conceder perdón a quienes fueron privados de la libertad, por la comisión de delitos en los que la culpa fue jurídicamente establecida.

\section{El Consejo de Ministros}

La Constitución vigente trata entre sus artículos 119 al 129 sobre el Consejo de Ministros. En realidad, carece de sentido el análisis de cada artículo en un ensayo como el presente. Salvo los trabajos de Chirinos Soto o de Torres Lara, ponente en el Congreso Constituyente Democrático del proyecto de la nueva Constitución, no hay expertos en materia constitucional que sostengan que la nueva constitución tiene algo de nuevo y positivo en relación al régimen de los Ministros de estado introducido en la Constitución vigente. Las severas críticas que Manuel Vicente Villarán formulara en su estudio sobre los ministros y el Consejo de Ministros en el anteproyecto de Constitución de 1931 se mantienen en plena vigencia a pesar del tiempo transcurrido y de las tres constituciones sucedidas desde entonces.

La opinión del maestro Villarán precisa que, en el Perú, poco importaba que los textos legales 
se refiriesen al establecimiento del régimen presidencial o al parlamentario porque el inadecuado tratamiento constitucional del modelo político y el excesivo protagonismo presidencial neutralizaban cualquier participación efectiva de los ministros. Así y referido a la figura del Presidente del Consejo de Ministros, Domingo García Belaunde transcribe el siguiente comentario de Manuel Vicente Villarán en su ya mencionado trabajo sobre los Ministros: "la institución de la presidencia del Consejo de Ministros no tiene la utilidad ni la importancia en que pensaron sus autores. El volumen político del Presidente de la República no deja sitio al Presidente Consejo de Ministros. La Presidencia del Consejo, débil de nacimiento, está atrofiada" (García Belaunde 1990). El caso se haya dentro de la lógica del sistema de gobierno presidencial que excluye como exótica e inadaptable la existencia de un jefe de gabinete que posea algo más sustancial que un título de honor y precedencia.

Tiene razón Domingo García Belaunde que califica la presidencia del Consejo de Ministros como "protocolaria, funcional y decorativa" (García Belaunde 1989, 153) y nada ha cambiado en la actual Constitución, donde el jefe del gabinete carece de funciones propias y el artículo 123 apenas si lo designa como "portavoz autorizado del gobierno" (inciso 1). ¿No es esta acaso una función propia de un jefe de prensa y no de un jefe de gabinete?

En realidad, es el Presidente de la República quien preside como Jefe de Gobierno al Gabinete, sus ministros devienen en meros colaboradores o secretarios a los que el Congreso puede cambiar cuantas veces le venga en gana. Tal vez la precaria situación constitucional de los ministros sea una de las causas de la escasa fragilidad del régimen político peruano. El gabinete puede estar bien conformado y tener un excelente presidente del consejo; pero eso políticamente no le garantizará la estabilidad, porque el problema principal proviene de esa terrible tradición política que concentra tanto poder en el Presidente de la República, que este se convierte en un rey sin corona ni cetro, rodeado de ministros, cuya duración en el cargo no depende tanto de la confianza, sino de la capacidad de doblegarse de la voluntad presidencial. Peor aún, su situación es tan incómoda que no faltarán circunstancias en que a pesar de haber obtenido a un alto costo la confianza del presidente, pueden haber caído en la desgracia de perder la del Congreso, que también tiene la capacidad de censurarlos o negarles confianza. En síntesis, la tragedia de un político o un tecnócrata que acepta ser ministro sufrirá de una doble dependencia de confianza, una del presidente y otra del Congreso.

No es menos cierto que las nuevas tendencias de la gestión pública han significado que algunos ministros vean decrecer la importancia de la cartera a su cargo. De un lado, es el modelo de privatización autorizado por la Constitución que les hace perder presencia en aspectos estratégicos de la gestión ministerial. Tal es el caso por ejemplo del Ministerio de Trabajo y por citar un asunto más actualizado el Ministerio de Salud y el Ministerio de Cultura que reciben una asignación presupuestal tan escasa que la capacidad de gestionar los asuntos a su cargo es mínima.

\section{Conclusiones}

El presente estudio que atiende a una gentil invitación a la revista IUS ET VERITAS de la Facultad de Derecho de la PUCP ha pretendido poner al día aspectos relativos a la ubicación del Presidente de la República en el contexto del modelo político que desarrolla la Constitución de 1993; soy consciente que por lo extenso del tema no he podido abarcar todos los aspectos que involucran y dan identidad política al Presidente de la República en el Perú. Al revisar el texto, observo que el tema de las relaciones del Presidente y sus ministros con el Poder Legislativo podría haber incluido asuntos como el control parlamentario de la gestión ejecutiva o el de la responsabilidad de los Ministros en lo que se refiere a las relaciones con el Poder Judicial, así como las que el Presidente mantiene con la seguridad y la defensa; podríamos haber tocado el artículo 167, que convierte al Presidente de la Republica en el jefe supremo de las Fuerzas Armadas, sin que exista leyes específicas que precisen los alcances y límites de las atribuciones y funciones que le compete al Jefe de Estado en esos campos de 
gobierno. En otros donde hay ausencia legislativa de lo que es el Presidente de la República en tanto el jefe de Estado y cómo se diferencia de ese cargo de la que le corresponde al Presidente como Jefe de Gobierno.

No obstante, fluyen de las disposiciones constitucionales analizadas y sobre todo de las tradiciones seculares, que son las que en verdad rigen las relaciones del Presidente de la República con los sectores populares mayoritarios en el país, que esto hace de la institución presidencial un régimen político sui géneris, porque no es estrictamente presidencial, ni parlamentario, ni mixto, sino una isla de poder, más cercana al caudillismo político que al republicanismo democrático más apegado al mando y dispongo que al riguroso respeto de la ley. Todo esto implica un sistema híbrido que depende en exceso del talento y de la capacidad de estadista de quien ocupa transitoriamente el cargo de presidente y debe evitar la tentación de administrar el poder, encarnándolo, autosuficientemente en su persona.

No se trata de un problema de mala fe, de mala voluntad o de ganas de ser autoritario; se trata, y hay muchos datos que confirman la hipótesis, de que el éxito del gobierno de un presidente en el Perú depende de la capacidad o más propiamente de su disposición para poner en práctica un populismo con más visos de autoritario que de democrática. ¿Qué pasa si incurre en la práctica ejercer el poder combinando las dos tendencias? Una actitud tan ambigua como la descrita está llena de peligros. Si se inclinan por el respeto a los modos democráticos, lo más probable es que sea tratado de medroso, frágil, inseguro y sometido a las presiones de los defensores de la juridicidad. Si por el contrario huyendo de los parámetros anteriores, el Presidente se refugia en las prácticas de los populismos demagógicos, lo más probable es que no tarde en convertirse en prisionero de ellos, concurriendo en prácticas autoritarias para mantenerse en el poder.

No creo, sinceramente lo digo, haber exagerado en estas líneas que contienen severas críticas, no a las personas sino a los errores con los que la Constitución en el Perú ha implementado el cargo de Presidente de la República. La vida y los cargos públicos que me han tocado desempeñar me han permitido conocer de cerca a casi todos los gobernantes peruanos desde los años 60 en adelante. He mantenido cordiales relaciones con ellos y siempre me he preocupado por observar un escrupuloso respeto al cargo y a la persona. Pero puedo dar fe de haber sido testigo de no pocos momentos de impaciencia y cólera presidencial, en situaciones en que literalmente se convertían en prisioneros de tradiciones cortesanas y populistas, ajenas a la posibilidad de gobernar, concentrándose en la obtención de las metas de democracia y desarrollo que tenían cuando llegaron a la presidencia. Con esta afirmación, lo que sostengo es que en el Perú el Presidente de la República puede convertirse en la principal víctima del presidencialismo exacerbado que lo rodea, de la debilidad de las instituciones que estructuran el Poder Ejecutivo, de exigencias antidemocráticas que lo presionan para alejarse de la democracia y gobernar como un autócrata. En verdad, mientras no seamos capaces de consolidar la democracia y regular mejor el ejercicio de los poderes del Estado, la desestabilización seguirá siendo un peligro latente; un peligro que no deja gobernar bien.

\section{Referencias Bibliográficas}

Barnechea, Alfredo. 1995. La República embrujada. Lima: Aguilar.

Basadre, Jorge. 1979. Perú: Problema y posibilidad. Lima: Banco Internacional del Perú. https://doi.org/10.2307/3633695

2002. La iniciación de la República. Lima: Fondo editorial de la UNMSM.

2006. Historia de la República del Perú. Lima: El Comercio.

Belaúnde, Víctor Andrés. 1994. La crisis presente 1914-1939. Lima: Luis Alfredo Ediciones.

Bernales, Enrique. 1988. Alcances constitucionales del poder presidencial. En La empresa privada y el orden constitucional, 87-99. Lima: CONFIEP. 
Enrique Bernales Ballesteros

1999. Crítica al presidencialismo en América Latina. Revista Araucaria 2: 155-66.

1994. Los poderes Ejecutivo-Legislativo en la Constitución de 1993. Buenos Aires: Fundación K. Adenauer - CIEDLA.

1995. La crisis de los partidos políticos. En Sociedad, Partidos y Estado en el Perú. Lima: Universidad de Lima.

2012. La Constitución de 1993: veinte años después. Lima: IDEMSA.

2013. El desarrollo de la Constitución de 1993 desde su promulgación a la fecha. Revista Pensamiento Constitucional 18: 35-46.

Blancas, Carlos. 2011. La cláusula de Estado Social en la Constitución. Análisis de los Derechos Fundamentales laborales. Lima: Fondo editorial de la PUCP.

Borea, Alberto. 2016. Manual de la Constitución. Para qué sirve y cómo defenderte. Lima: Biblioteca peruana de Derecho Constitucional.

Burdeau, Georges. 1983. El liberalismo político. Buenos Aires: Editorial Universitaria.

Cairo, Omar. 2015. La responsabilidad política institucional en el Perú. Revista Pensamiento Constitucional 20: 35-46.

Castillo Freyre, Mario. 1997. Todos los poderes del Presidente (ética y derecho en el ejercicio de la Presidencia). Lima: Fondo Editorial de la PUCP.

Chirinos Soto, Enrique. 1994. La Constitución de 1993: lectura y comentario. Lima: Normay.

Cotler, Julio. 1986. Clases, Estado y Nación en el Perú. Lima: Instituto de Estudios Peruanos.

Duverger, Maurice. 1970. Les régimes politiques. Paris: Que sais Je.

Eguiguren, Francisco. 1991. Relaciones entre Ejecutivo y Legislativo. Lima: Comisión Andina de Juristas.

2007. La responsabilidad constitucional y penal del Presidente de la República en el Perú: propuestas para su reforma. Tesis para optar el grado de Doctor en Humanidades, Pontificia Universidad Católica del Perú.

Fernández Segado, Francisco. 1994. El nuevo ordenamiento constitucional del Perú: aproximación a la Constitución de 1993. Revista de Estudios Políticos 84 (abril-junio): 27-68.

García Belaunde, Domingo. 1989. Teoría y práctica de la Constitución peruana. Tomo I. Lima: EDDILI.

1990. Funciones legislativas del Ejecutivo moderno: el caso peruano. Revista internacional de ciencias administrativas: revista de administración pública comparada 3: 169-90.

1991. Constitución y Política. 2a ed. Lima: SEGLUSA.

García Belaunde, Domingo y Pedro Planas Silva. 1993. La Constitución traicionada: páginas de historia reciente. Lima: SEGLUSA.

Hakansson, Carlos. 2013. El neo presidencialismo oculto en la Constitución de 1993. En La Constitución de 1993 a veinte años de su promulgación. Aciertos, desaciertos y propuestas de reforma. Lima: Universidad Ricardo Palma.

Hobbes, Thomas. 1952. Leviatán. Las Cruces: Enciclopedia Británica.

Landa, César. 2013. Del constitucionalismo autoritario al constitucionalismo democrático. En La Constitución de 1993 a veinte años de su promulgación. Aciertos, desaciertos 
y propuestas de reforma. Lima: Universidad Ricardo Palma.

Linz, Juan. 2013. Los peligros del presidencialismo. Revista Latinoamericana de Política Comparada 7 (julio): 11-31.

Loewenstein, Karl. 1970. Teoría de la Constitución. Barcelona: Ariel.

Otárola, Alberto. 1997. Reelección presidencial y derecho de referéndum. Lima: Fundación Hans Seidel.

Planas, Pedro. 1997. Regímenes políticos contemporáneos. $2^{\mathrm{a}}$ ed. México, D.F.: Fondo de Cultura Económica.

Proust, Marcel. 1970. En busca del tiempo perdido. 7. El tiempo recobrado. Madrid: Alianza.

Quiroga, Aníbal. 1985. La interpretación constitucional. Revista Derecho PUCP 39: 323-43.
Rodríguez, Iván. 2013. La Constitución de 1993 a veinte años de su promulgación. Aciertos, desaciertos y propuestas de reforma. Lima: Universidad Ricardo Palma.

Rubio, Marcial. 2000. Estudio de la Constitución Política de 1993. Tomo III y V. Lima: Fondo Editorial de la PUCP.

2005. La interpretación constitucional según el Tribunal Constitucional. Lima: Fondo Editorial de la PUCP.

Rubio, Marcial y Enrique Bernales. 1983. Constitución y Sociedad Política. 3a ed. Lima: Mesa Redonda.

1988. Constitución: fuentes e interpretación: teoría y documentación del proceso constitucional y la Constitución de 1979. Lima: Mesa Redonda.

Torres y Torres Lara, Carlos. 1993. La nueva Constitución del Perú 1993: antecedentes, fundamentos e historia documentada. Lima: Asesorandina.

Valle-Riestra, Javier. La responsabilidad constitucional del Jefe de Estado. Lima: Labrusa. 